\title{
Satellite monitoring of the environment in the area of the Iskitim coal mines in 2013-2020
}

\author{
Natalia V. Rodionova ${ }^{1}$ \\ ${ }^{1}$ Kotel'nikov FIRE RAS, Fryazino, Russia
}

\begin{abstract}
The paper considers the use of multispectral data from the Landsat-8, Sentinel-2, Aqua and Terra satellites for monitoring pollution in the areas of open-pit coal mines in the Iskitim district of the Novosibirsk region for the period 2013-2020. The change in the values of the reflection coefficient (RC) from the surface and water bodies, the snow index NDSI during the snowmelt period, the change of NDVI in the summer, in the area of Kolyvansky and Vostochny coal mines and in the area of the Linevo village are considered. The dynamics of the aerosol optical thickness (AOT) changes, $\mathrm{CO}$ and $\mathrm{CH}_{4}$ concentrations in the atmosphere of the Iskitim district using the Giovanni data analysis and visualization system are shown.
\end{abstract}

\section{Keywords}

Remote sensing, multispectral images, coal mine, surface and air pollution.

\section{Introduction}

Open-pit coal mining, its transportation have a negative impact on the environment, polluting the surface and air with emissions of solid substances in the form of coal and inorganic dust, coal ash and soot. In addition, more active coal mining is the cause of man-made earthquakes due to the movement of rocks [1]. Over the past 10 years, the frequency of earthquakes in the Novosibirsk region has increased-this is directly related to active coal mining. One of the last earthquakes occurred in September 2020 in the vicinity of the Kolyvansky coal mine (CM) near the village of Ust-Chem.

Satellite images make it possible to assess the area and degree of pollution of the territories adjacent to coal mining, mainly during the snowmelt period.

In this paper, satellite monitoring of snow cover pollution in the Iskitimsky district of the Novosibirsk region near Kolyvansky and Vostochny CM and in the vicinity of the Novosibirsk Electrode Plant in the village of Linevo was carried out using multispectral data from the Landsat-8 (L8) and Sentinel-2 (S2) satellites to determine the dynamics of changes in the values of the reflection coefficient from the surface, the NDSI snow index during snowmelt and the NDVI vegetation index in summer for the period 2013-2020. The work also makes an assessment of atmospheric pollution based on the use of data from the Terra/Aqua satellites. The estimated parameters include the aerosol optical thickness, $\mathrm{CO}$ and $\mathrm{CH}_{4}$ concentrations in the atmosphere of Iskitim district using the Giovanni data analysis and visualization system [2].

SDM-2021: All-Russian conference, August 24-27, 2021, Novosibirsk, Russia

@rnv1948123@yandex.ru (N.V. Rodionova)

(c) (1) ๑ 2021 Copyright for this paper by its authors. Use permitted under Creative Commons License Attribution 4.0 International (CC BY 4.0).

CEUR Workshop Proceedings (CEUR-WS.org) 


\section{Materials and methods}

\subsection{Input data and study area}

The work uses Landsat-8 OLI C2 L2 images with radiometric calibration and atmospheric correction, which can be accessed for free, for example, through the EarthExplorer service [3]. The channels used (B2-B7) of each image were converted from the brightness values DN to the reflectivity values of the underlying surface. The spatial resolution for multispectral channels is $30 \mathrm{~m}$. Cloudless images of early April (snowmelt) and summer (July-August) 2013-2020 were used.

The work also uses Sentinel-2 multispectral data with high temporal, spatial, and spectral resolution. The multispectral camera has 13 channels with different spatial resolutions from 10 to 60 meters. We used data from the S2 survey system with the L2A processing level in the form of an albedo at the lower boundary of the atmosphere (with atmospheric correction). S2 data processing was carried out by the program SNAP [4]. S2 images were used in cases when Landsat 8 images were missing or covered in clouds.

For the analysis of atmospheric pollution, we used the NASA Goddard online visualization and analysis tool Giovanni [2] which allows usage, comparison, and analysis voluminous remote sensing (RS) data (NASA MODIS (Terra and Aqua), ESA MERIS (ENVISAT)) without downloading.

The study area is located in the Iskitimsky district of the Novosibirsk region (Eastern Siberia). Iskitim district is a territory with a high technogenic load. There are several coal basins with open-pit coal mining, a cement plant (Iskitim), the Novosibirsk Electrode Plant (Linevo), the raw material base for which is anthracite deposits. All this, as well as all the processes associated with the operation of coal mines, transportation of coal, lead to negative consequences for the natural environment.

Figure 1 shows the study area in the image S2, channel B4, the date of the survey 02.04.2020, with a characteristic view of snow cover contamination in the area of Iskitim (cement plant) (1),

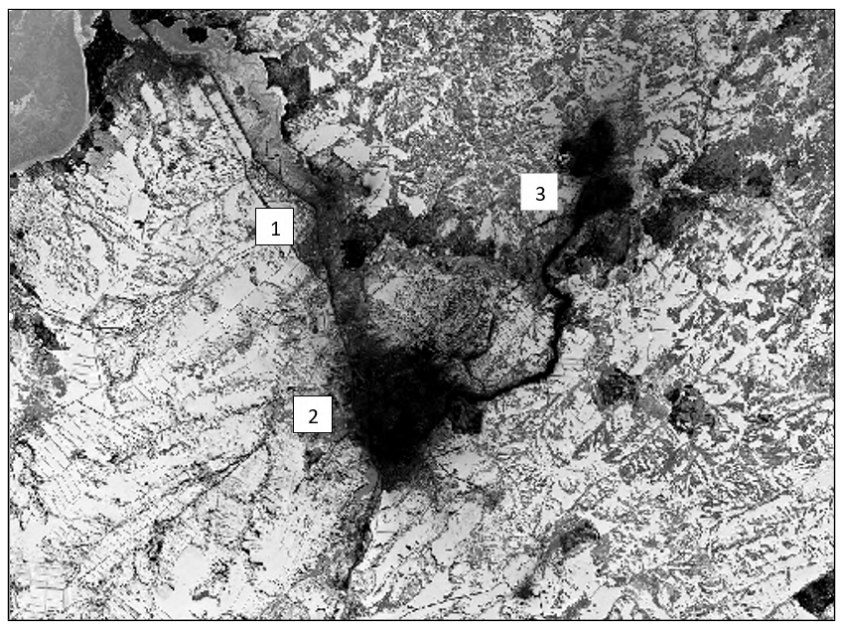

Figure 1: Image S2 of Iskitim region, channel B4, 02.04.2020. 
the village of Linevo (Novosibirsk Electrode Plant) (2), the areas of the Kolyvansky and Vostochny coal mines (3), Urgunsky, Gorlovsky coal mines and highways along which coal is transported. The upper left part of the image shows a fragment of the Ob reservoir.

\subsection{Assessment of anthropogenic impact on surface pollution}

It is shown [5] that the minimum time interval for the study of man-made impacts from mining on the environment is a period of 5 years. In this paper, this period is equal to 8 years from 2013 to 2020.

\subsubsection{Snow cover during snowmelt}

To assess the level of surface pollution in the winter-spring period, the assessment of snow cover pollution during the snowmelt period is used. Snow cover, having a cumulative effect, allows to get the real total amount of precipitation of pollutants. The evaluation criteria are the reflective characteristics of the snow cover in various spectral channels and snow indices, one of which is the snow index NDSI (normalized difference snow index) [6], defined as

$$
\mathrm{NDSI}=\frac{\text { GREEN }- \text { SWIR1 }}{\text { GREEN }+ \text { SWIR1 }}
$$

The threshold for identifying snow is the value NDSI $\geq 0.4$ [6].

Let's compare the reflection coefficient (RC) from the snow cover and NDSI near Linevo (Figure 1, (2)) and Kolyvansky coal mine (Figure 1, (3)) in 2013 and 2020.

The number of coal mines in the Kolyvansky district increased from 2013 to 2020 (Figure 2, L8 images).

Figure 3 shows graphs of changes in the reflection coefficient and NDSI along the profiles in the Kolyvansky and Vostochny CM region during the snowmelt for 09.04.2013 (L8) (top row) and 02.04.2020 (S2) (bottom row). Profile consists of 14 points. The distance in $\mathrm{km}$ from the "zero point" is plotted along the abscissa axis (the value of $0 \mathrm{~km}$ corresponds to the point with coordinates $54^{\circ} 39^{\prime} 47^{\prime \prime} \mathrm{N}, 83^{\circ} 37^{\prime} 30^{\prime \prime} \mathrm{E}$, near the road to CM. The NDSI value for all points of the

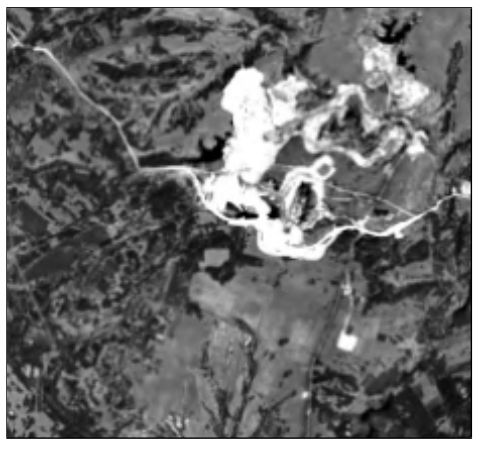

14.07.2013

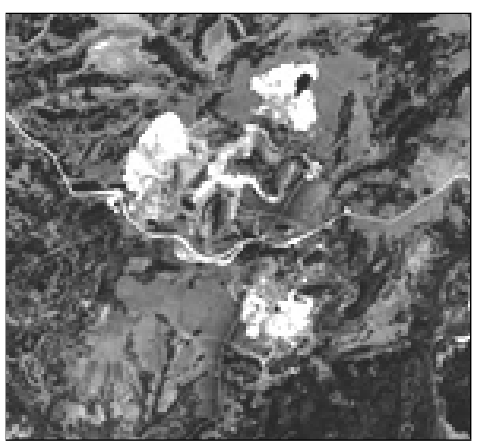

11.06.2016

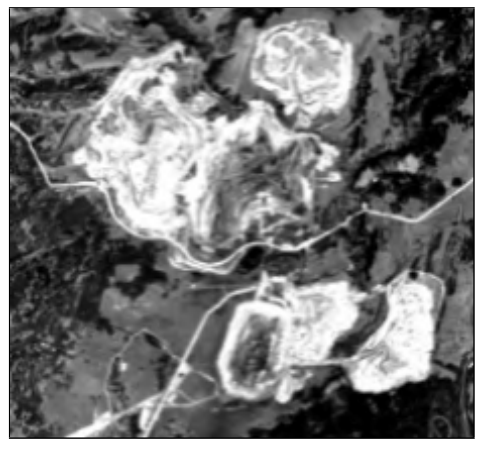

02.08.2020

Figure 2: Dynamics of changes of the Kolyvansky and Vostochny coal mine territory from 2013 to 2020 according to L8 data. 
L8, 09.04.2013
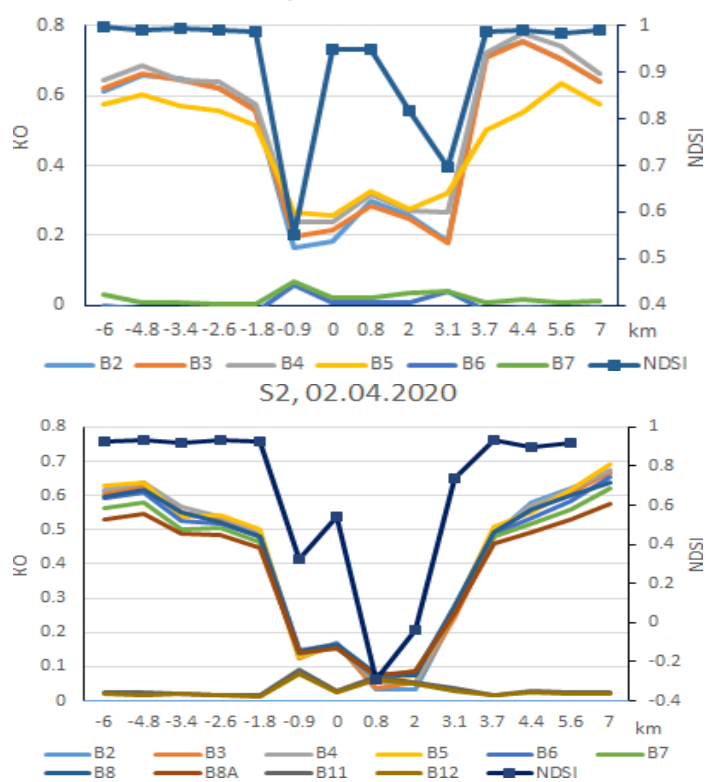
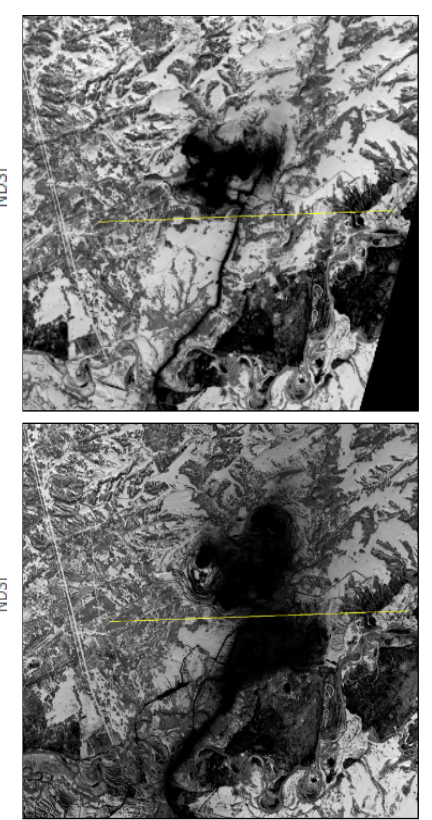

Figure 3: Graphs of the RC and NDSI change for the profile in the area of Kolyvansky and Vostochny coal mines for April 2013 and 2020.
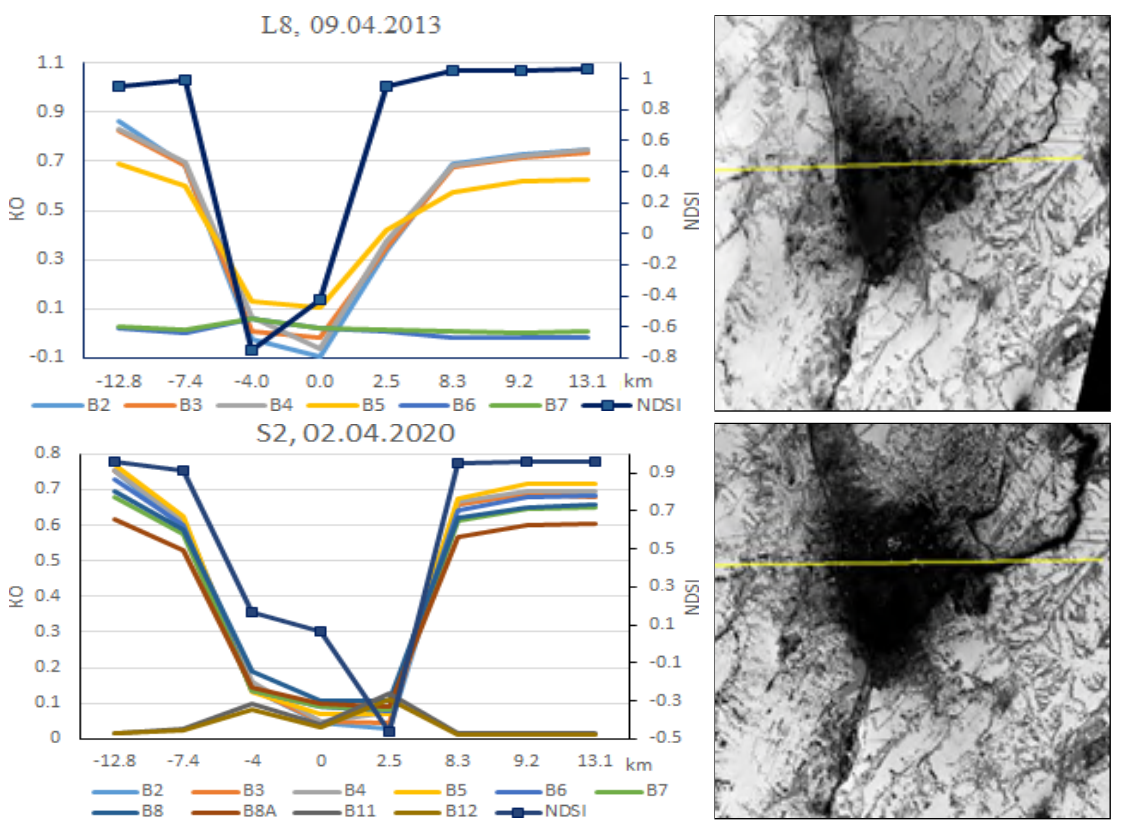

Figure 4: RC and NDSI change along the profile for 09.04.2013 (L8) and 02.04.2020 (S2).

2013 profile is greater than 0.5, i.e. snow is identified at these points. For 2020, snow has not been identified for profile points up to $2.5 \mathrm{~km}$ in the direction of Ust-Chem (from 0 point) and about $1.2 \mathrm{~km}$ (from 0 point) in the western direction. 
Snow pollution in the area of Linevo is associated with the work of the Novosibirsk electrode plant (NEP). Dust removal from high-rise pipes of the plant, coal processing, quarry operations, and technological route in the vicinity of the plant are the main sources of pollution in this area. Figure 4 shows the graphs of RC and NDSI changes for April 9, 2013 (L8) (top row) and April 2, 2020 (S2) (bottom row) (snowmelt) along the 8-point profile passing through Linevo. The distance in $\mathrm{km}$ from the "zero kilometer" is plotted along the abscissa axis (the value of $0 \mathrm{~km}$ corresponds to the point with coordinates $54^{\circ} 31^{\prime} 15^{\prime \prime} \mathrm{N}, 83^{\circ} 24^{\prime} 05^{\prime \prime} \mathrm{E}$, near the NEP). The snow-free zone in 2020 compared to 2013 has practically not changed in the direction to the west from the 0 point, at the same time it has expanded in the eastern direction by $4-5 \mathrm{~km}$.

\subsubsection{Vegetation}

To assess the state of vegetation, integral characteristics are used, expressed in the form of vegetation indices (VI). The basis for the choice of VI is the features of the reflectivity curves of vegetation, namely, in the red region of the spectrum (RED), the maximum absorption of solar radiation by chlorophyll is noted, in the near infrared (NIR), the maximum reflection of energy by the cellular structure of the leaf. As a result, the normalized difference index

$$
\mathrm{NDVI}=\frac{\mathrm{NIR}-\mathrm{RED}}{\mathrm{NIR}+\mathrm{RED}}
$$

is the most common method for quantifying the phytomass density. Technogenic factors associated with the open-pit coal mining method have a negative impact on the vegetation cover. Pollution of the atmosphere, soil, water environment, etc. are factors of impaired growth and development of vegetation.

In this paper, the values of RC and NDVI for the profile in the village of Linevo are compared according to L8 data for the summer time period for the dates 30.07.2013 and 02.08.2020 (Figure 5, the profile is the same as in Figure 4).

Note in Figure 5 the local minimum of the values of the RC at the point of "zero" km (near the NEP). The NDVI values for all points of the profile, except for the $9.2 \mathrm{~km}$ point, for 2013 exceed the NDVI values for 2020.

Figure 6 shows RGB images of the studied territory for the summer period, demonstrating the dynamics of changes in the values of NDVI $=(\mathrm{B} 5-\mathrm{B} 4) /(\mathrm{B} 5+\mathrm{B} 4)(\mathrm{L} 8$ channels $)$ for
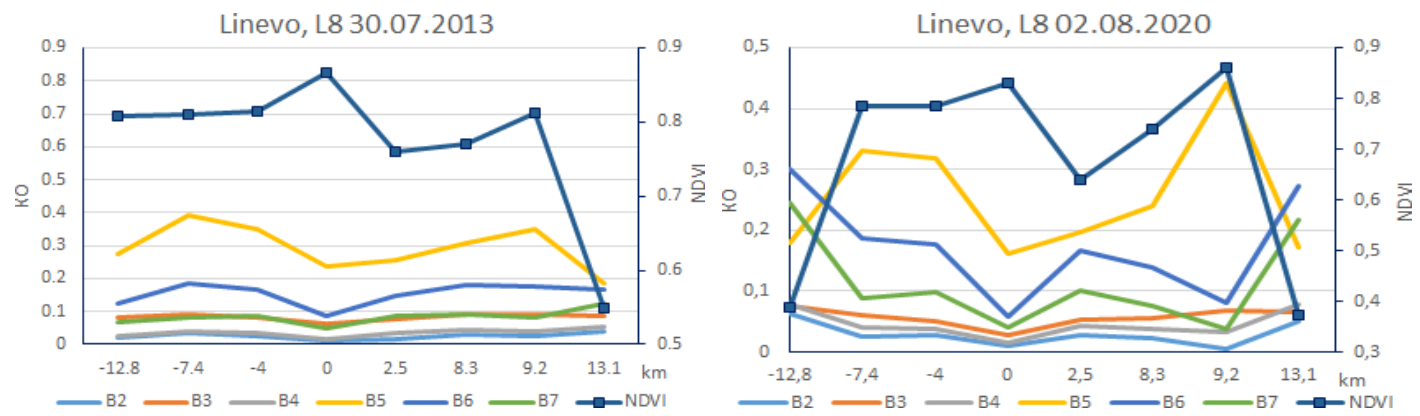

Figure 5: RC and NDVI changes for 30.07.2013 and 02.08.2020. 


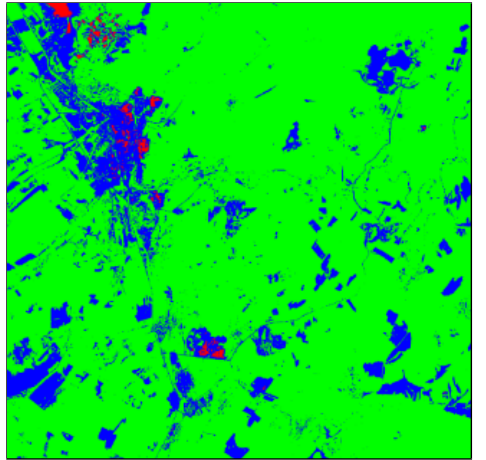

30.07 .2013

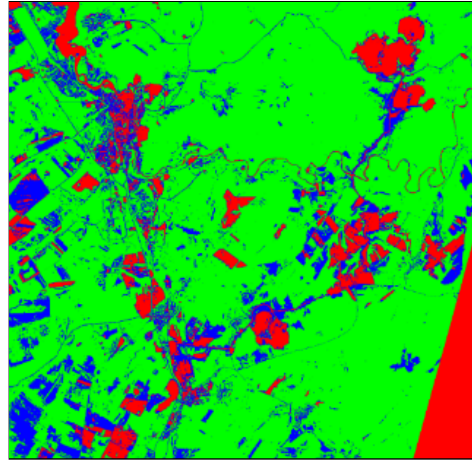

04.08 .2018

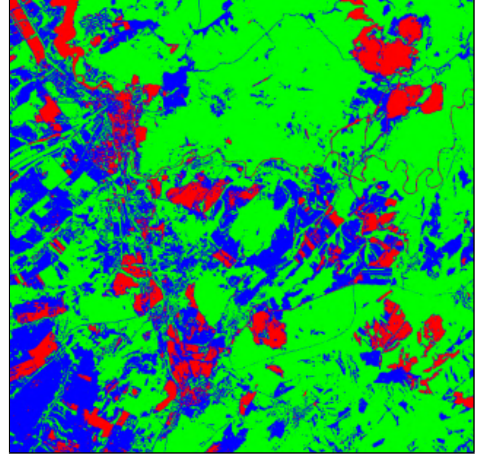

02.08 .2020

Figure 6: RGB images of NDVI value changes.

dates 30.07.2013, 04.08.2018 and 02.08.2020 with the following encoding of NDVI values: red NDVI $<0.4$, green - NDVI $>0.7$, blue - NDVI $\geq 0.4$ and NDVI $\leq 0.7$. There is a tendency from 2013 to 2020 to increase the territories with NDVI $<0.7$.

\subsubsection{Water bodies}

In Figure 7, the numbers in the image Landsat-8 (B5, 2.8.2020) indicate the monitoring water objects. These are: 1 - the Ob reservoir; 2 - the Berd River near the bridge; 3 - the Berd River; 4 - the Linevo Lake; 5 - the Koinikha Lake. The spectral curves for the wavelengths of

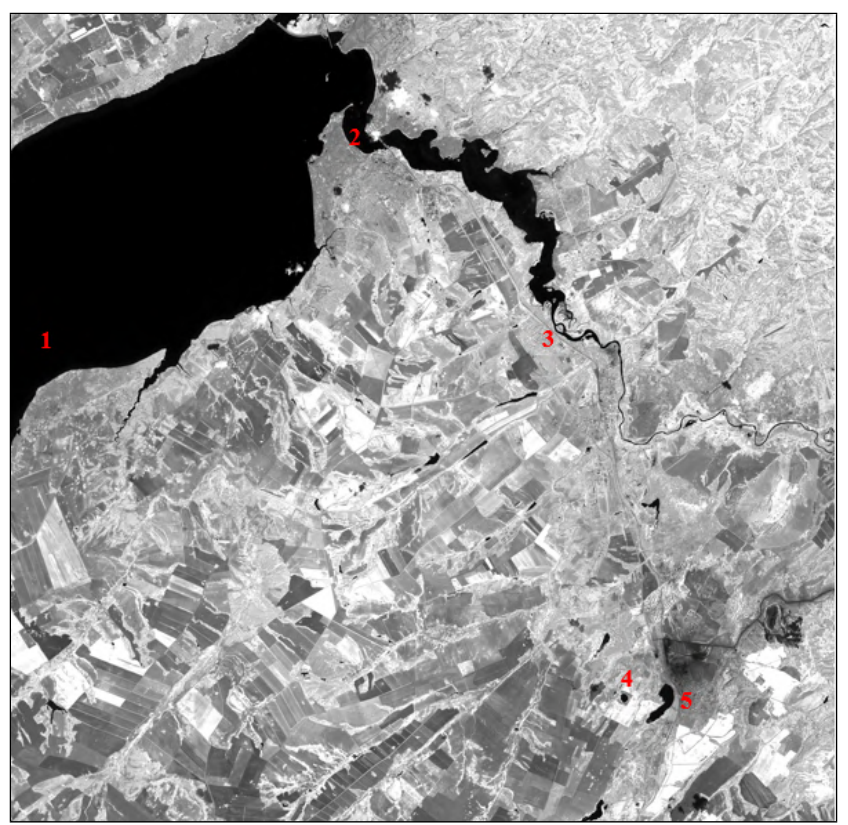

Figure 7: Location of water bodies monitoring points. 
L8 B2-B7 are shown in Figure 8 for four dates 30.07.2013, 08.07.2014, 31.07.2019 and 02.08.2020. The spectral curves for 2014 and 2019 are presented here to demonstrate a significant difference between the spectral curves for 2013 and for 2014-2020 in terms of the RC value in the B5 channel (NIR). The data in 2013 are characterized by a significant increase in RC in three and more times in NIR channel for the considered water bodies except for the Ob reservoir.

In the work [7], it is shown that the two spectral zones NIR and SWIR are very sensitive to the presence of impurities in a water medium. In closed reservoirs (Lake Linevo), such impurities settle to the bottom, while for water bodies with an active current of water the particles are mixed, which causes a jump in the amount of RC. Moreover, the presence of suspended particles in the water medium increases the RC in NIR spectrum, and organic substances in SWIR1. For 2013, there are two peaks in the RC values: in the green region of the B3 spectrum and in NIR (B5). The first maximum is present on all the charts presented. The increase RC in B3 channel is associated with an increase in the volume of phytoplankton, while there is a decrease in the red zone of the B4 spectrum, which is associated with the absorption of chlorophyll by plankton and so a decrease RC in the B4 channel. For all graphs, the smallest changes in channels B3 and B4 were found for object 4 - Lake Linevo (except 2013).

The second maximum (channel B5) is associated with the presence of suspended impurities in the water medium. In 2013, the value of the RC for B5 is in three and more times higher than the RC for 2014-2020. The exception is the value of the RC for the Ob reservoir, for which the values of the RC in the channel B5 are the smallest relative to the other considered water bodies. The second maximum, pronounced in 2013, gradually comes to naught since 2014, and the $\mathrm{RC}$ values gradually decrease during the transition from the $\mathrm{B} 5$ channel to the $\mathrm{B} 7$ channel.
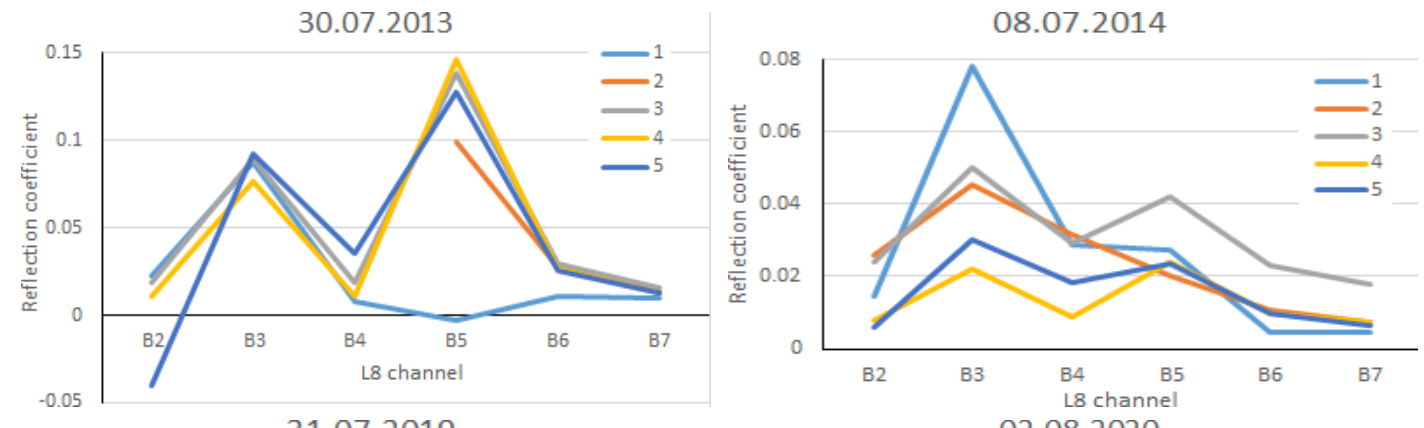

31.07.2019
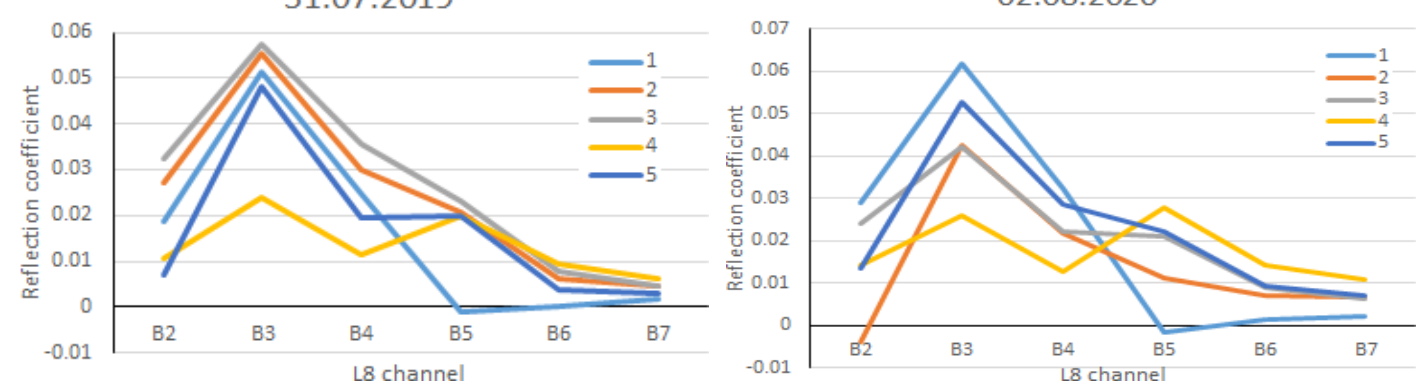

Figure 8: Spectral curves for water bodies: 1 - Ob reservoir; 2 - the Berd River near the bridge; 3 - the Berd River; 4 - the Linevo Lake; 5 - the Koinikha Lake. 
Based on the values of the $\mathrm{RC}$ for the $\mathrm{B} 5$ channel, the Ob reservoir is the cleanest. The present contamination is suspended particles, inorganic impurities.

\subsection{Assessment of air pollution}

Iskitim is one of the cities with a high level of air pollution (AP). The substances that determine the level of AP in Iskitim are benz(a)pyrene, suspended substances (dust), $\mathrm{CO}$ - carbon monoxide, $\mathrm{NO}_{2} / \mathrm{NO}$ - dioxide/nitrogen oxide, $\mathrm{SO}_{2}$ - sulfur dioxide, hydrogen sulfide and soot. Iskitim is located in a low-lying area, which contributes to the accumulation of harmful substances in the air above the city.

This paper examines the dynamics of changes in the aerosol optical thickness (AOT), CO and $\mathrm{CH}_{4}$ values in the atmosphere of Iskitim district in 2013-2020 using the Giovanni data analysis and visualization system [2].

\subsubsection{Seasonal and interannual variations of AOT}

Among the radiation-significant components of the atmosphere, along with greenhouse gases and clouds, an important role plays atmospheric aerosol, the main optical characteristic of which is the AOT of the atmosphere. Aerosol particles have a significant effect in the temperature balance of the atmosphere, as they are able to absorb, disperse, reflect solar radiation and initiate cloud formation processes. The main natural factors that affect the long-term variability of AOT are volcanic eruptions [8] and forest fires [9]. In open-pit coal mining, the main pollutants are solid emissions: inorganic dust, coal dust, coal ash, and soot. For the analysis of spatiotemporal variations of AOT, data from satellite measurements, in particular the MODIS radiometer of the Terra/Aqua satellites, are increasingly used.

To estimate atmospheric aerosol variations, we used data from the level 3 (average daily) collection 6.1 of the MODIS radiometer (Terra satellite) - the product Terra MOD08_D3 v6. 1 (Deep Blue, Land only) at a wavelength of $550 \mathrm{~nm}$. The AOT data obtained with MODIS is a two-dimensional field (image) integrated in height. The dimensions of the individual elements (pixels) of the map are $1 \times 1^{\circ}$ (latitude $\times$ longitude). The average monthly AOT values for the period April-October 2013-2020 were calculated, averaged for a $1 \times 1^{\circ}$ domain with a center coordinates $54.5^{\circ} \mathrm{N}, 83.5^{\circ} \mathrm{E}$, using the Giovanni data analysis and visualization system [2].

Figure 9 shows the average long-term AOT values for the months of April-October 2013-2020 and SD AOT.

We note the seasonal course of atmospheric turbidity with a maximum in the spring-summer period (April and July) and a minimum in the autumn (there are no data for the winter period). Similar trends have been observed for the Baikal region [10]. An increased AOT values in April is observed for the entire study period. In July the increased AOT values most pronounced for 2019, and slightly weaker for 2016. We should note also the strong spread of AOT values in July 2019 (see SD AOT values). One of the main reasons for the April AOT maximum in Iskitim region is the release by snowmelt of aerosol accumulated during the winter period in the snow cover. The local minimum in May can be associated with the formation of fresh vegetation cover and an increase in rain level that washes out the aerosol. The AOT maximum in July is most likely associated with an increase in temperature, a decrease in humidity and drought. 

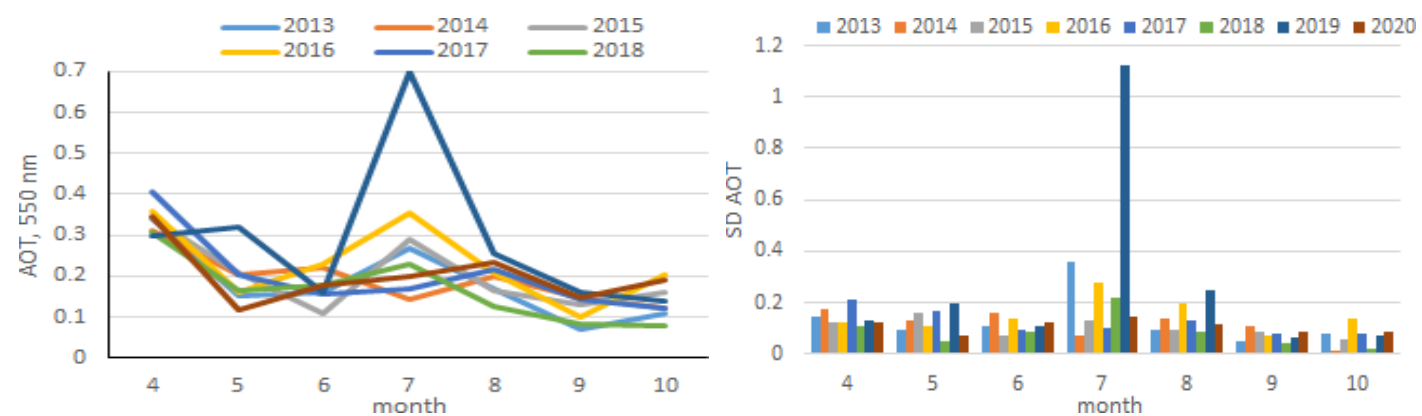

Figure 9: Average AOT and SD AOT values for April-October 2013-2020 for the study area according to MODIS (Terra) data.

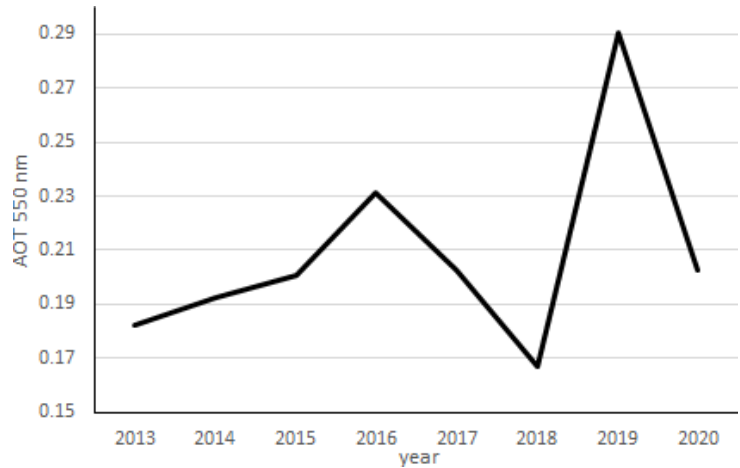

Figure 10: Interannual variations of AOT for the period 2013-2020.

Figure 10 shows a graph of the interannual variations of AOT for the period 2013-2020. No annual trends were found.

Large variations of the interannual AOT values have been detected. Only for 2018, the average AOT value is close to the average annual global value of 0.16 , obtained from satellite data MODIS, TOMS, AVHRR [11]. For the rest of the dates for the Iskitim region, the average long-term value of AOT is significantly higher than average annual global value and the value for the Baikal region (data from MODIS and ground-based solar photometer measurements [10]).

\subsubsection{Seasonal and interannual variations of $\mathrm{CO}$}

The main sources of $\mathrm{CO}$ are the burning of fossil fuels, biomass, and the atmospheric oxidation of methane and other hydrocarbons. Carbon monoxide is a colorless and odorless gas. CO is formed by the combustion of organic fuels (wood, coal, paper, oils, gasoline, etc.). The dominant part $(\sim 90 \%)$ of atmospheric CO is formed as a result of natural processes (volcanic and swamp gases, forest and steppe fires, the vital activity of terrestrial and oceanic flora and fauna). At the same time, about $70 \%$ of the $\mathrm{CO}$ in the atmosphere is the product of methane oxidation in the troposphere with the participation of the hydroxyl radical $(\mathrm{OH})$. On a global scale, atmospheric methane (which is oxidized by $\mathrm{OH}$ ) is the main source of $\mathrm{CO}$ in the atmosphere. In large cities and industrial regions, the preponderance may be on the side of $\mathrm{CO}$, directly emitted from 
anthropogenic sources. Hundreds of millions of tons of $\mathrm{CO}$ enter the atmosphere annually as a result of human activities: motor transport, rail and sea transport; malfunction of gas pipelines and gas equipment; metallurgy, chemical, coal mining, tobacco, bread production, light copying; waste processing; fuel combustion in everyday life. In industry, $\mathrm{CO}$ is produced by incomplete oxidation of natural gas or by gasification of coal and coke. $\mathrm{CO}$ enters the atmospheric air during any type of combustion. In cities $\mathrm{CO}$ gets into the air, mainly in the composition of exhaust gases from internal combustion engines. CO has a long life time - about a month [13].

Daily data of the AIRS/Aqua instrument product AIRS3STM v006, averaged over an area of $54-55^{\circ} \mathrm{N}, 83-84^{\circ} \mathrm{E}$ were used to study variations in the atmospheric CO content. Figure 11, a shows the average monthly values of the $\mathrm{CO}$ concentration and Figure 11, b shows the SD values for the period 2013-2020 (common for all the 8 years from 2013 to 2020 are 1) the highest concentrations of $\mathrm{CO}$ occur in the winter months, as well as in the spring months of March and April. The summer months are characterized by the lowest concentrations of $\mathrm{CO}$. The $\mathrm{CO}$ concentration values in the autumn months are higher than in the summer months, but lower than in the winter months.

Figure 12 shows the average annual CO concentrations for 2014-2020. The averaging was carried out for 11 months (the month of July was not included due to the lack of data for 2014-2018). The chart does not include data for 2013, because, except for July, there is no data

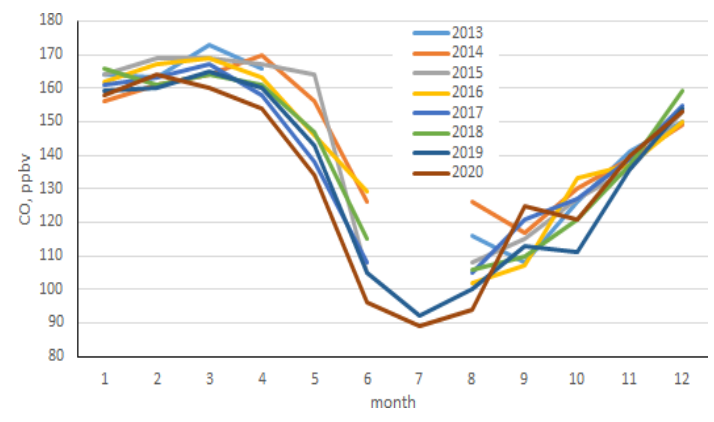

a

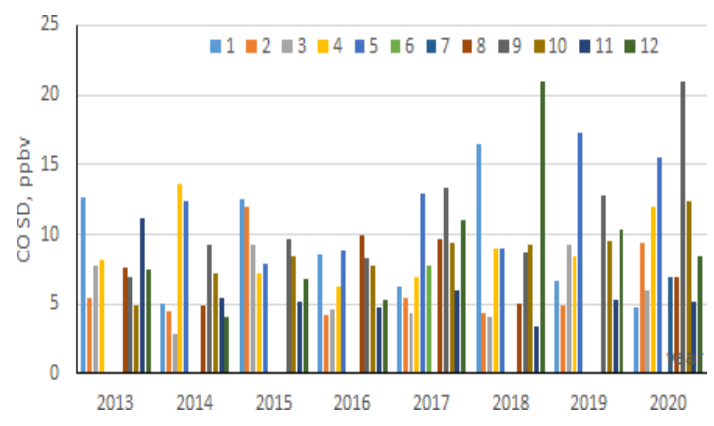

$\mathrm{b}$

Figure 11: Average monthly changes in carbon monoxide concentration, averaged over the site $54-55^{\circ} \mathrm{N}$, $83-84^{\circ} \mathrm{E}$.

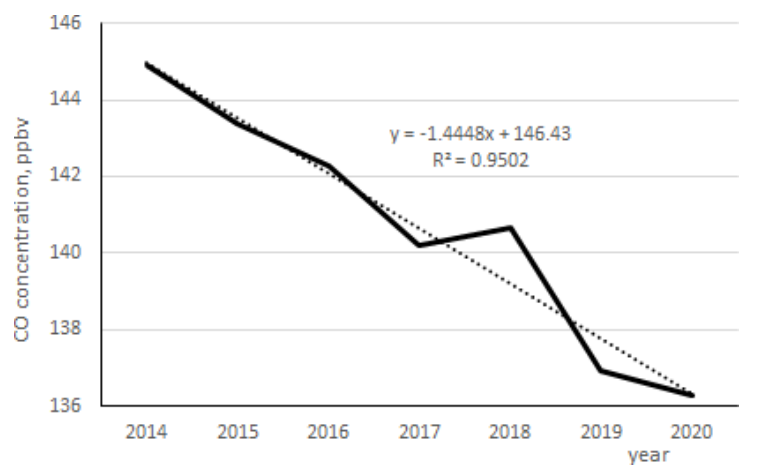

Figure 12: Average annual CO concentrations for 2014-2020. 
for May for this year. The trend line with the coefficient of determination $R^{2}=0.95$ indicates a stable decrease in the CO concentration for 7 years from 2014 to 2020. In 2014, the average annual CO concentration is $0.145 \mathrm{ppm}=0.168 \mathrm{mg} / \mathrm{m}^{3}$. The average annual value for 2020 is $0.136 \mathrm{ppm}=0.158 \mathrm{mg} / \mathrm{m}^{3}$. The MAC (Maximum Allowable Concentration) for CO is the average daily MACad $=0.05 \mathrm{mg} / \mathrm{m}^{3}$ and the MAC single MACs $=0.15 \mathrm{mg} / \mathrm{m}^{3}$ [13].

\subsubsection{Seasonal and interannual variations of $\mathrm{CH}_{4}$}

Methane enters the atmosphere as a result of both natural and anthropogenic processes. The main natural source of methane emissions into the atmosphere is wetlands. Methane is formed primarily as a result of the activity of bacteria involved in the decomposition of organic matter. Therefore, the main places of methane formation are swamps, garbage dumps, etc. In addition, methane is released through cracks in the earth's crust at the bottom of water bodies, during mining operations, and during the burning of forests. Anthropogenic sources of methane in the atmosphere are energy production from coal and natural gas, landfills, sewage treatment plants, agricultural (manure processing), rice farming, and biomass burning. Methane is released during the production and transportation of coal, natural gas, and oil. After the release, methane remains in the atmosphere for approximately 8.4 years, after which it is removed mainly by chemical oxidation in the troposphere. The main mechanism for removing methane from the atmosphere is its oxidation in the upper atmosphere by the hydroxyl radical $\mathrm{OH}$, which is formed by sunlight from ozone and water vapor.

Figure 13 shows a histogram of the average monthly values of $\mathrm{CH}_{4}$ concentrations and SD value, based on the daily average data of the AIRS (Atmospheric Infrared Sounder) infrared spectrometer installed on the EOS AQUA satellite, AIRS3STD v.7.0 product. These are maps of daily methane distributions with a resolution of $1 \times 1^{\circ}$ at a baric altitude of $1000 \mathrm{hPa}$, available at the link [2]. There are no values for the summer months in the product.

According to Figure 13, an increase in the methane concentration was observed for the autumn months (September-November). So the maximum value for September is $1.99 \mathrm{ppm}$, for October $1.97 \mathrm{ppm}$, for November $1.966 \mathrm{ppm}$. The decline in values was noted in April-May (there is no data for the summer months). The minimum value for May is $1.87 \mathrm{ppm}$. The maximum values of the SD do not exceed 3\% of the average monthly values of methane concentration. The average concentration of $\mathrm{CH}_{4}$ in the atmosphere is $1.86 \mathrm{ppm}$ [14]. For the autumn months,
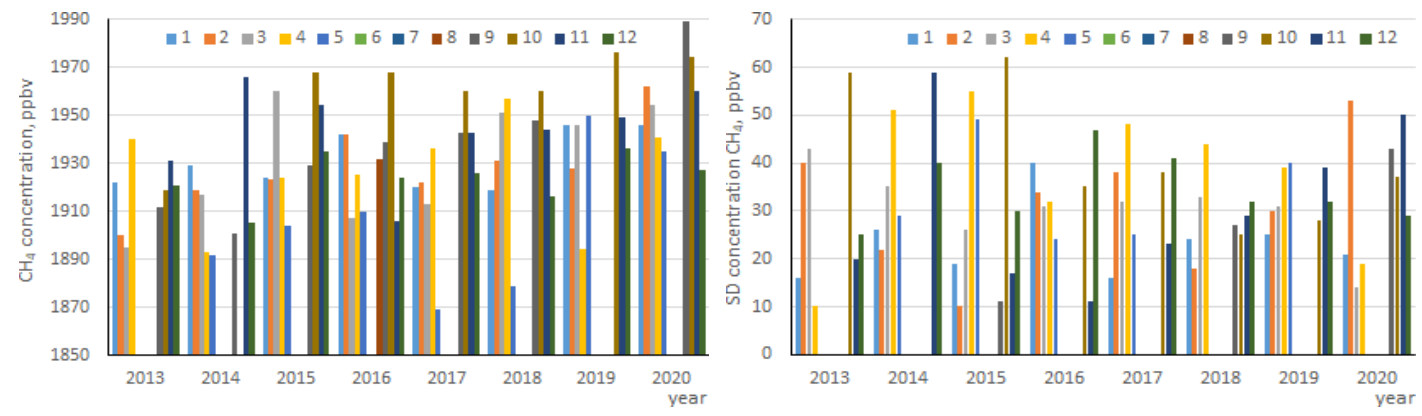

Figure 13: Monthly methane concentrations and SD values for 2013-2020. 


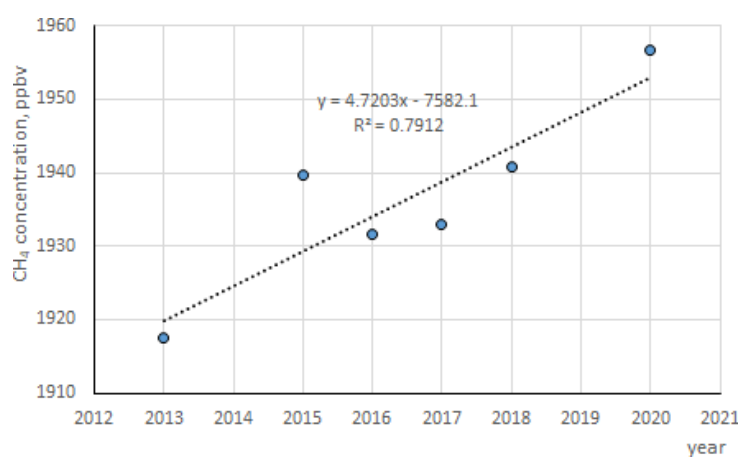

Figure 14: Average annual values of $\mathrm{CH}_{4}$ concentration (no summer months).

the methane concentration for the study area exceeds the average value for the atmosphere.

Figure 14 shows a graph of the average annual values of the $\mathrm{CH}_{4}$ concentration averaged over 8 months (January-April, September-December), where the trend line with the coefficient of determination $R^{2}=0.79$ shows a steady increase in the methane concentration over the period 2013-2020. For 2013, the average methane concentration is $1.92 \mathrm{ppm}=1.3 \mathrm{mg} / \mathrm{m}^{3}$, and for $2020,1.957 \mathrm{ppm}=1.32 \mathrm{mg} / \mathrm{m}^{3}$.

\section{Conclusions}

According to satellite monitoring data of the Iskitimsky district with a high technogenic load, the following changes have been outlined in the ecology of the region for the period 2013-2020. The dirty snow zone expanded eastward by 3-5 km over the period 2013-2020 in the area of Linevo and Kolyvansky and Vostochny coal mines. A decrease in the NDVI values was noted in these areas. It is shown the dynamics of changes in the aerosol optical thickness (AOT), CO and $\mathrm{CH}_{4}$ values in the Iskitim district. The seasonal change of AOT with the maximum values in April and July is shown. Only for 2018, the average AOT value is close to the average annual global value of 0.16 . For the rest of the dates for the Iskitim region, the average long-term value of AOT is significantly higher than average annual global value. The highest concentrations of $\mathrm{CO}$ occur in the winter months, as well as in the spring months of March and April. The summer months are characterized by the lowest concentrations of $\mathrm{CO}$. The $\mathrm{CO}$ concentration values in the autumn months are higher than in the summer months, but lower than in the winter months. The trend line with the coefficient of determination $R^{2}=0.95$ indicates a stable decrease in the CO concentration for 7 years from 2014 to 2020 , and increase in the methane concentration with the coefficient of determination $R^{2}=0.79$.

\section{Acknowledgments}

The work was carried out within the framework of the state assignment of the Kotel'nikov FIRE RAS on the topic 0030-2019-0008 "Space". 


\section{References}

[1] https://ngs.ru/text/gorod/2020/09/28/69479455.

[2] http://giovanni.gsfc.nasa.gov.

[3] https://earthexplorer.usgs.gov.

[4] https://sentinel.esa.int/web/sentinel/toolboxes/sentinel-1.

[5] Purkis S., Klemas V. Remote sensing and global environmental change. UK, USA: WileyBlackwell, 2011.

[6] Hall D.K., Riggs G.A., Salomonson V.V. Development of methods for mapping global snow cover using Moderate Resolution Imaging Spectroradiometer (MODIS) data // Remote Sensing of Environment. 1995. Vol. 54(2). P. 127-140.

[7] Oparin V.N., Potapov V.P., Giniyatullina O.L. O kompleksnoj ocenke sostoyaniya okruzhayushchej sredy po dannym distancionnogo zondirovaniya Zemli v regionah $\mathrm{s}$ vysokoj tekhnogennoj nagruzkoj // Fiziko-Tekhnicheskie Problemy Razrabotki Poleznyh Iskopaemyh. 2014. No. 6. P. 199-209.

[8] Bryson R.A., Goodman B.M. Volcanic activity and climatic changes // Science. 1980. Vol. 207. P. 1041-1044.

[9] Sakerin S.M., Gorbarenko E.V., Kabanov D.M., Osobennosti mnogoletnei izmenchivosti aerozol'noi opticheskoi tolshchiny atmosfery i otsenki vliyaniya razlichnykh faktorov // Optika Atmosfery i Okeana. 2008. Vol. 21. No. 7. P. 625-631.

[10] Tashchilin M.A., Yakovleva I.P., Sakerin S.M. Prostranstvenno-vremennye variacii aerozol'noj opticheskoj tolshchi v Bajkal'skom regione // Sovremennye Problemy Distancionnogo Zondirovaniya Zemli iz Kosmosa. 2021. Vol. 18. No. 1. P. 219-226.

[11] Chubarova N., Nezval Ye., Sviridenkov M., Smirnov A., Slutsker I. Smoke aerosol and its radiative effects during extreme fire event over Central Russia in summer 2010 // Atmospheric Measurement Techniques. 2012. Vol. 5. P. 557-568.

[12] Deryugina A.B. Analiz lokal'nyh izmerenij koncentracii CO v g. Petergof. 2017. Available at: http://elib.rshu.ru/files_books/pdf/rid_8cfe04d7c0304f5587627e49f20d451a.PDF.

[13] https://vozdyx.ru/article/pdk-vrednyx-veshhestv-v-atmosfernom-vozduxe.

[14] Repina I. Remote studies of methane concentrations and fluxes in the atmosphere. Available at: http://d33.infospace.ru/d33_conf/tarusa2015/07.pdf. 